\title{
Mivacurium-induced neuromuscular block in adult patients suffering from Charcot-Marie- Tooth disease
}

\author{
[Le blocage neuromusculaire induit par le mivacurium chez des patients adultes \\ atteints de la maladie de Charcot-Marie-Tooth]
}

Hubert J. Schmitt MD, Tino Münster MD

Purpose: The response to non-depolarizing neuromuscular blocking drugs is variable in patients with Charcot-Marie-Tooth (CMT) disease. We speculated that CMT involvement of the monitored muscle may be partially responsible for this inconsistency. We therefore investigated the response to a standard dose of mivacurium simultaneously assessed at adductor pollicis (AP) and orbicularis oculi (OO) muscles in five patients with CMT.

Clinical features: Over a period of one year, five adult patients with CMT scheduled for orthopedic surgery were studied. The right arm and the right supercilliary arch were prepared for acceleromyographic (AMG) neuromuscular monitoring. The AMG probes were attached at the distal interphalangeal joint of the right thumb and on the right upper eyelid to record the response of the AP and $\mathrm{OO}$, respectively. The ulnar nerve and upper part of the facial nerve were stimulated supramaximally with repeated train-of-four stimuli $(2 \mathrm{~Hz}, 0.2 \mathrm{msec})$ every I 5 sec via applied surface electrodes. Following monitor calibration and induction of general anesthesia, mivacurium $0.2 \mathrm{mg} \cdot \mathrm{kg}$ I iv was given, and the time course of relaxation and recovery were assessed. Times to spontaneous recovery of TI to $25 \%$ were $15 \pm 3$ vs $12 \pm 4 \mathrm{~min}$ in the AP and $\mathrm{OO}$ muscle groups respectively, whereas times to $90 \%$ recovery were $23 \pm 5$ vs $29 \pm 10 \mathrm{~min}$, respectively.

Conclusion: The onset and recovery characteristics associated with mivacurium-induced neuromuscular block were similar at the AP and $\mathrm{OO}$ muscle groups. A near normal response to mivacurium was observed in this small series of patients with CMT disease.
Objectif : La réaction aux curarisants non dépolarisants varie d'un patient à l'autre dans la maladie de Charcot-Marie-Tooth (CMT). En supposant qu'une atteinte du muscle sous observation et déjà atteint par la maladie MCT était partiellement responsable de cette variation, nous avons vérifié la réponse à une dose habituelle de mivacurium simultanément à l'adducteur du pouce (AP) et au muscle orbiculaire des paupières $(O P)$ chez cinq patients atteints de CMT.

Éléments cliniques : Au cours d'une année, cinq patients adultes atteints de CMT et opérés en orthopédie ont été étudiés. Le bras droit et l'arcade sourcilière ont été préparés pour un monitorage de la transmission neuromusculaire accéléromyographique (AMG). Les sondes d'AMG ont été fixées à l'articulation interphalangienne distale du pouce droit et à la paupière supérieure droite pour l'enregistrement des réponses respectives des AP et $O P$. Le nerf cubital et la partie supérieure du nerf facial ont été soumis à des stimuli supramaximaux en train-de-quatre $(2 \mathrm{~Hz}, 0,2 \mathrm{~ms}$ ) toutes les $15 \mathrm{~s}$ par les électrodes appliquées. Après le calibrage du moniteur et l'induction de l'anesthésie générale, $0,2 \mathrm{mg} \cdot \mathrm{kg}^{-1} \mathrm{de}$ mivacurium iv ont été donnés et l'évolution du relâchement musculaire et de la récupération a été évaluée. Les temps de récupération spontanée de Tlà $25 \%$ ont été respectivement de $15 \pm 3$ vs 12 \pm 4 min à l'AP et à l'OP, alors que les temps de récupération à $90 \%$ ont été respectivement de $23 \pm 5$ vs $29 \pm 10 \mathrm{~min}$.

Conclusion : Les caractéristiques du délai d'installation et de la récupération associés au blocage neuromusculaire induit par le mivacurium ont été similaires pour les groupes musculaires AP et $O P$. Une réponse au mivacurium, près de la normale, $a$ été observée chez cinq patients atteints de la maladie de CMT.

From the Department of Anesthesiology, Friedrich-Alexander University Erlangen-Nuremberg, Erlangen, Germany.

Address correspondence to: Dr. Hubert J. Schmitt, Department of Anesthesiology, Friedrich-Alexander Universität, Erlangen-

Nuremberg, Krankenhausstrasse 12, D-91054 Erlangen, Germany. Phone: 9131-85-33680; Fax: 9131-85-36147;

E-mail: hubert.schmitt@kfa.imed.uni-erlangen.de

No funding except departmental was provided.

None of the authors has a conflict of interest.

Accepted for publication May 5, 2006.

Revision accepted July 13, 2006. 


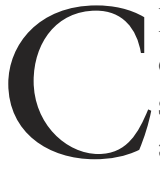

HARCOT-MARIE-TOOTH

$(\mathrm{CMT})$ disease, also known as hereditary motor sensory neuropathy or peroneal muscular atrophy, comprises a heterogeneous group of inherited neurological disorders with an estimated prevalence of four per 10,000. Recent genetic investigations have shown that despite similar degrees of clinical involvement, the genetic etiology of the disease is heterogeneous. ${ }^{1}$ The syndrome is caused by demyelination and/or loss of axons of the peripheral nerve fibres resulting in peripheral muscular weakness, the leading clinical feature. Until recently, it was believed that involvement of upper extremities occurs only in the late stages of the disease. However, recent evidence suggests that axonal loss of upper arm nerves in adult CMT may occur at an early stage of the disorder without overt clinical manifestations. ${ }^{2}$

One of the main anesthetic concerns in patients with CMT is the choice of neuromuscular blocking drugs (NMBDs). Though it is commonly accepted not to use depolarizing NMBDs, the response of CMT patients to non-depolarizing NMBDs is mainly based on retrospective reviews with conflicting results. The reported effects of nondepolarizing NMBDs in adult CMT patients range from attenuated to increased. However, in most cases these reported effects were evaluated by clinical observation only, without quantitative documentation. ${ }^{3-7}$ While quantitative assessment by electromyography (EMG) may be difficult in the routine clinical setting, ${ }^{8}$ the peripheral nerve chosen for stimulation seems to be of critical importance in monitoring the effects of muscle relaxants in patients with this disease.

We speculated that subclinical involvement of upper extremities nerve fibres may account for conflicting reports regarding the time course of NMB in CMT. The aim of this investigation was to evaluate in a small series of adults suffering from CMT, the pharmacodynamic profile of mivacurium-induced NMB, quantitatively assessed by acceleromyography (AMG). In order to identify or exclude possible involvement of the upper extremity nerve fibres, we simultaneously monitored NMB at the adductor pollicis (AP) and orbicularis oculi (OO) muscles. We chose OO for comparative recordings because cranial nerves are seldom affected, or have involvement only at advanced stages of the disease.

\section{Methods}

With institutional Research Ethics Board approval and informed consent we studied over a one year period five patients with CMT scheduled for orthopedic surgical procedures. In all patients the diagnosis of CMT disease had been based on clinical findings. Four patients had a positive family history. In four patients the diagnosis had been ascertained by genetic testing and classified as CMT 1A (duplication 17p1 1.2). ${ }^{1}$ On examination, all patients presented with typical clinical symptoms of the disease including high foot arches and distal wasting of the lower limbs. Three patients had progressive difficulty in walking, but they were independently ambulatory. The other two patients were only mildly disabled. Neurological examination revealed reduced strength in the anterior tibialis and peronealis muscles of all subjects, and decreased or absent reflexes in the lower extremities. No patient showed signs of involvement of the upper extremities, and none had facial nerve palsy.

Following application of routine monitors in the operating room, Ringer's lactate solution $500 \mathrm{~mL}$ was administered, followed by preoxygenation with $100 \%$ $\mathrm{O}_{2}$. Anesthesia was induced with alfentanil $20 \mu \mathrm{g} \cdot \mathrm{kg}^{-1}$ iv followed by a target-controlled infusion of propofol (target concentration $\left.4 \mu \mathrm{g} \cdot \mathrm{kg}^{-1}\right)$. Following loss of consciousness the patient's trachea was intubated and the lungs were mechanically ventilated (oxygen/air) with minute ventilation adjusted to maintain the $\mathrm{P}_{\mathrm{ET}} \mathrm{CO}_{2}$ between $32-35 \mathrm{mmHg}$. Anesthesia was maintained with propofol (target concentration 2-3 $\mu \mathrm{g} \cdot \mathrm{kg}^{-1}$ ) and alfentanil boluses of $10 \mu \mathrm{g} \cdot \mathrm{kg}^{-1}$ in titrated to effect. A warm forced air device was used to maintain body temperature at $36^{\circ} \mathrm{C}$ monitored by an ear probe.

After positioning for surgery, the patient's right arm and the right upper eye lid were prepared for AMG neuromuscular monitoring. An AMG probe (thumb adapter, TOF-Watch SX, Organon, Nijmegen, The Netherlands) was attached at the distal interphalangeal joint of the right thumb. To record the response of the $\mathrm{OO}$, an $\mathrm{AMG}$ probe (eye-adapter) was placed on the right upper eye lid. ${ }^{9}$ The ulnar nerve and upper part of the facial nerve were stimulated supramaximally with repeated train-of-four (TOF) stimuli $(2 \mathrm{~Hz}, 0.2 \mathrm{msec})$ every $15 \mathrm{sec}$ via applied surface electrodes (Fisher \& Paykel, Auckland, New Zealand). The time course of NMB from both recording sites was simultaneously registered online by two portable PCs (TOF Watch SX monitor program, Organon, Nijmegen, The Netherlands). The automatic calibration set-up of the TOF watch SX was used to determine supramaximal stimulation at both sites (single twitch, $0.1 \mathrm{~Hz}$ ). Following calibration, a signal stabilization phase for the control response was established over a period of at least two minutes. Thereafter, a bolus of mivacurium $0.2 \mathrm{mg} \cdot \mathrm{kg}^{-1} i v$ was administered over $15 \mathrm{sec}$. The AMG response from the time of drug administration 
TABLE I Patient characteristics

\begin{tabular}{lllllllll}
\hline Patient & Sex F/M & Age $(\mathrm{yr})$ & BMI $\left(\mathrm{kg} \cdot \mathrm{m}^{-2}\right)$ & ASA & Family history & Sensation & $\begin{array}{l}\text { Preoperative } \\
\text { echocardiogram }\end{array}$ & $\begin{array}{l}\text { Preoperative } \\
\text { ECG }\end{array}$ \\
\hline l & F & 24 & 22 & II & yes & normal & normal & normal \\
2 & F & 25 & 19.9 & II & no & normal & normal & normal \\
3 & M & 20 & 18.8 & II & yes & normal & normal & normal \\
4 & F & 48 & 22.8 & II & yes & impaired & normal & normal \\
5 & F & 30 & 22 & II & yes & normal & normal & normal \\
\hline
\end{tabular}

$\mathrm{ASA}=$ American Society of Anesthetiologists classification; BMI = body mass index; ECG = electrocardiogram.

TABLE II Time course of neuromuscular block at the orbicularis oculi and adductor pollicis muscles

\begin{tabular}{lcc}
\hline Time course & Orbicularis oculi & Adductor pollicis \\
\hline Lag time $(\mathrm{sec})$ & $53 \pm 8$ & $62 \pm 11$ \\
Onset $(\mathrm{sec})$ & $150 \pm 57$ & $125 \pm 22$ \\
$\mathrm{~T}_{10}(\mathrm{~min})$ & $10 \pm 5$ & $12 \pm 3$ \\
$\mathrm{~T}_{25}(\mathrm{~min})$ & $12 \pm 4$ & $15 \pm 3$ \\
$\mathrm{~T}_{90}(\mathrm{~min})$ & $29 \pm 10$ & $23 \pm 5$ \\
Recovery index $(\mathrm{min})$ & $9 \pm 4$ & $6 \pm 2$ \\
Recovery time $(\mathrm{min})$ & $10 \pm 6$ & $13 \pm 7$ \\
\hline Values are expressed as mean \pm SD. Lag time = time between \\
mivacurium administration and first change of (train-of-four \\
(TOF) response; onset time = time between injection of mivacuri- \\
um and more than 95\% depression of the first twitch; $\mathrm{T}_{10}, \mathrm{~T}_{25}, \mathrm{~T}_{90}$ \\
$=$ time between mivacurium administration and recovery of first \\
twitch of the TOF response to 10,25 and $90 \%$; recovery index $=$ \\
time between 25 and 75\% recovery of first twitch; recovery time \\
$=$ time between 25\% recovery of first twitch and recovery of TOF \\
ratio to 90\%.
\end{tabular}

until complete spontaneous recovery was evaluated, to establish the following variables: i) lag time, ii) onset time, iii) time of recovery of first twitch response to $10 \%, 25 \%, 75 \%$, and $90 \%$ of the baseline response, and iv) recovery time (time between $25 \%$ recovery of first twitch and recovery of TOF ratio of $90 \%$ ). The recovery index (the time of recovery of first twitch from $25 \%$ and $75 \%$ of baseline) was also calculated. ${ }^{10}$ No subsequent mivacurium or other NMBD was administered following the initial dose, and after recovery from mivacurium, the remainder of the anesthetic was continued according to the discretion of the attending anesthesiologist.

\section{Results}

The patient characteristics are summarized in Table I. The time course of NMB in response to mivacurium is summarized in Table II. From the site of the AP, mivacurium $\left(0.2 \mathrm{mg} \cdot \mathrm{kg}^{-1} i v\right)$ induced a peak effect of $100 \%$ paralysis (complete $\mathrm{NMB}$ ) in all patients, whereas the maximum response ranged between $90 \%$ to $100 \%$ of twitch depression in the $\mathrm{OO}($ mean $\pm \mathrm{SD}, 98 \pm 5 \%)$. In all but one patient onset of NMB was faster at the $\mathrm{AP}$ in comparison with the $\mathrm{OO}(125 \pm 22$ vs $150 \pm 57$ sec, respectively). Mean duration of block was similar at both recording sites. However, there was relatively wide inter-patient variability, as reflected in the large standard deviations. In three patients spontaneous recovery was more rapid at the $\mathrm{OO}$, in one patient it was more rapid at the $\mathrm{AP}$, whereas in the fifth patient recovery time from mivacurium was nearly identical at both recording sites. Complete spontaneous recovery was achieved in all patients as documented by return of twitch amplitude to baseline values at both recording sites. There were no adverse events during anesthesia in any patient, and adequate restoration of spontaneous ventilation and return of airway reflexes was present in all patients at the end of surgery.

\section{Discussion}

In this case series we have shown that in adult patients with CMT, onset and recovery from $\mathrm{NMB}$ at the thumb is similar to simultaneously recorded tracings at the OO. Using an intravenous anesthetic technique to minimize drug interactions, mivacurium $(0.2$ $\mathrm{mg} \cdot \mathrm{kg}^{-1}$ iv) was associated with complete $\mathrm{NMB}$ at both recording sites. Spontaneous recovery was minimally affected compared to the response observed in patients without neuromuscular disease.

Onset and recovery in response to mivacurium were similar to the clinical response in patients without neurological disease. ${ }^{9}, 11$ In contrast to the reported trend of a faster onset of $\mathrm{NMB}$ at the $\mathrm{OO}$ as reported by Rimaniol et al. ${ }^{11}$ there was no observable trend in our series of patients. In three of five CMT patients, onset of NMB was faster at the AP. Despite the fact that wide inter-patient variability in recovery from mivacurium-induced $\mathrm{NMB}$ reflected the established pharmacodynamic variability in normal subjects, the time to $25 \%$ recovery of $\mathrm{T}_{1}$ amplitude at the $\mathrm{AP}$ as well as the $\mathrm{OO}$ was shorter in comparison to other published series ${ }^{9}$ (mean 15 vs $20 \mathrm{~min}$, and 12 vs 
16, respectively). Comparing the clinical duration to $90 \%$ recovery of $\mathrm{T}_{1}$ amplitude, variations from patients with normal neuromuscular function were discernible. Despite the small differences between $\mathrm{OO}$ and AP, recovery at both recording sites was similar to that observed in normal patients. ${ }^{11}$ The question of whether or not subclinical involvement of the monitored muscles may have contributed to the non-uniformity of response cannot be answered from this database. The patient with the longest duration of NMB was only mildly disabled. These data are consistent with a recent investigation in five children where a normal response to mivacurium was observed. ${ }^{12}$

These findings are difficult to compare with historical data, as assessment of neuromuscular function during anesthesia has been inconsistently documented in patients with CMT disease. ${ }^{3-7}$ The reported duration of $\mathrm{NMB}$ ranges from normal to very prolonged following administration of different nondepolarizing NMBDs. From these reports, there is no identifiable pattern. There are several possible explanations for the discrepancies.

First, the type of monitoring and recording site must be considered. Regardless of the clinical presence or absence of muscle weakness, the ulnar nerve may be affected in CMT patients. ${ }^{2}$ The leading electrophysiological feature in CMT disease is an overall reduction in motor conduction velocity. The slowing of nerve conduction velocity often precedes clinical manifestations of the disease as recent investigations have shown. ${ }^{13}$ In addition, in many CMT patients the amplitude of the compound muscle action potential of the upper extremities can be markedly reduced. ${ }^{14}$ Both these findings directly impair electromyographic assessment of neuromuscular transmission and in single cases result in an inability to record compound muscle action potentials by EMG., ${ }^{4,8}$ We used AMG for assessment of neuromuscular function, a method which evaluates acceleration of the stimulated muscle group independently from nerve conduction velocities. With AMG, we were able to evaluate the complete time course of NMB in all patients at both the $\mathrm{OO}$ and the AP muscles. Within our series, recovery of the $\mathrm{OO}$ correlated well with that of the AP, and in this respect the monitored muscles responded similarly to muscles of normal individuals. ${ }^{11}$ Due to differences between EMG and AMG, comparison of our data with reports of EMG findings in CMT patients is limited. Considering the pathophysiology of the underlying disease and the documented technical problems using EMG in CMT patients ${ }^{4,8}$ in our opinion, AMG has benefits for monitoring neuromuscular function in this situation.
Second, the stage of the disease is another important element to consider. Though onset and rate of progression of the disease may vary widely amongst CMT patients, there is a tendency for the disease to progress over time as a result of axonal degeneration leading to secondary muscle weakness. ${ }^{2}$ Different stages of disease progression may explain the reported differences in response to nondepolarizing NMBDs with CMT patients. No patient in our series showed signs of upper extremity weakness.

Third, the type of CMT may influence the response to nondepolarizing NMBDs. As mentioned previously, the group of CMT diseases is quite heterogeneous, whether classified on the basis of electrophysiologic findings or molecular diagnosis. ${ }^{1}$ The classical symptoms including weakness and sensory loss of lower or upper extremities vary widely amongst different types of CMT, and accordingly, so does the grade of disability. Of particular importance to the anesthesiologist is the fact that several rare types of CMT have phrenic nerve involvement which may cause diaphragmatic weakness, even in early stages of the disease. ${ }^{15}$ All patients in this series suffered from the demyelinating form of CMT (CMTl), as confirmed in four subjects by genetic testing (duplication on chromosome 17).

Fourth, the anesthetic technique must be considered. In all previous cases reporting delayed recovery in patients with CMT disease, volatile anesthetics had been administered. ${ }^{3,4,7}$ Volatile anesthetics potentiate the effects of nondepolarizing NMBDs independently from their own muscle relaxant effects. Therefore, it is conceivable that in CMT patients with varying degrees of muscle weakness, volatile anesthetics may have prolonged recovery independently from the effects of the NMBD used. We specifically avoided volatile anesthetics in our series. A normal response to different nondepolarizing NMBDs is also documented in two case reports of CMT patients using an anesthetic technique without volatile anesthetics. ${ }^{5,6}$

In summary, we recorded the complete time course of mivacurium-induced $\mathrm{NMB}$ and spontaneous recovery characteristics at the $\mathrm{AP}$ and the $\mathrm{OO}$ muscles in five adult patients suffering from CMT. We observed a similar onset and recovery profile in both muscle groups, and a near normal response to mivacurium in this small series.

\section{References}

1 Reilly MM, Hanna MG. Genetic neuromuscular disease. J Neurol Neurosurg Psychiatry 2002; 73(Suppl2): II12-21.

2 Birouk N, Gouider R, Le Guern E, et al. CharcotMarie-Tooth disease type 1A with 17pl1.2 duplication. 
Clinical and electrophysiological phenotype study and factors influencing disease severity in 119 cases. Brain 1997; 120(Pt 5): 813-23.

3 Brian JE, Boyles GD, Quirk JG Jr, Clark RB. Anesthetic management for cesarean section of a patient with Charcot-Marie-Tooth disease. Anesthesiology 1987; 66: 410-2.

4 Kotani N, Hirota K, Anzawa N, Takamura K, Sakai T, Matsuki $A$. Motor and sensory disability has a strong relationship to induction dose of thiopental in patients with the hypertropic variety of Charcot-MarieTooth syndrome. Anesth Analg 1996; 82: 182-6.

5 Baraka AS. Vecuronium neuromuscular block in a patient with Charcot-Marie-Tooth syndrome. Anesth Analg 1997; 84: 927-8.

6 Naguib M, Samarkandi AH. Response to atracurium and mivacurium in a patient with Charcot-Marie-Tooth disease. Can J Anaesth 1998; 45: 56-9.

7 Pogson D, Telfer J, Wimbush S. Prolonged vecuronium neuromuscular blockade associated with Charcot Marie Tooth neuropathy. Br J Anaesth 2000; 85: 914-7.

8 Fiacchino F, Grandi L, Ciano C, Sghirlanzoni A.

Unrecognized Charcot-Marie-Tooth disease: diagnostic difficulties in the assessment of recovery from paralysis. Anesth Analg 1995; 81: 199-201.

9 Hemmerling TM, Schmidt J, Hanusa C, Wolf T, Schmitt $H$. Simultaneous determination of neuromuscular block at the larynx, diaphragm, adductor pollicis, orbicularis oculi and corrugator supercilii muscles. $\mathrm{Br} \mathrm{J}$ Anaesth 2000; 85: 856-60.

10 Viby-Mogensen J, Engbaek J, Eriksson LI, et al. Good clinical research practice (GCRP) in pharmacodynamic studies of neuromuscular blocking agents. Acta Anaesthesiol Scand 1996; 40: 59-74.

11 Rimaniol JM, Dhonneur G, Sperry L, Duvaldestin P: A comparison of the neuromuscular blocking effects of atracurium, mivacurium, and vecuronium on the adductor pollicis and the orbicularis oculi muscle in humans. Anesth Analg 1996; 83: 808-13.

12 Schmitt HJ, Wick S, Muenster T. Onset and duration of mivacurium-induced neuromuscular blockade in children with Charcot-Marie-Tooth disease. A case series with five children. Pediatr Anesth 2006; 16: 182-7.

13 Krajewski KM, Lewis RA, Fuerst DR et al. Neurological dysfunction and axonal degeneration in Charcot-Marie-Tooth disease type 1A. Brain 2000; 123(Pt 7): 1516-27.

14 Lawson VH, Gordon Smith A, Bromberg MB. Assessment of axonal loss in Charcot-Marie-Tooth neuropathies. Exp Neurol 2003; 184: 753-7.

15 Nathanson BN, Yu DG, Chan CK. Respiratory muscle weakness in Charcot-Marie-Tooth disease. A field study. Arch Intern Med 1989; 149: 1389-91. 